\title{
El cuerpo y la policía. Una mirada de la incorporación y de la subjetivación en la educación a través de la película "Tropa de Élite"
}

\section{The body and the police. Incorporation and subjectification in education through a look of the film "Tropa de Elite"}

\author{
Eduardo Galak ${ }^{1}$
}

\begin{abstract}
RESUMEN
El presente artículo es un análisis de la película "Tropa de Élite" (2007), ganadora del prestigioso "Oso de oro" ("Goldener Bär"), a la mejor película en el Festival de Cine de Berlín (Berlinale), en el cuál se trabajan principalmente los conceptos "cuerpo" y "policía", y secundariamente los de "educación", "la política" y "lo político". La idea, entonces, es pensar a la policía en un doble sentido: coloquial y académico. A través de los personajes de André Matias y Nascimento se narra las vidas de dos agentes de policías con historias distintas pero con una recurrencia que nos permite pensarlas críticamente: desde la teoría de la subjetivación política es posible observar los espacios en los que se manifiestan disciplinamientos de los cuerpos, incorporados y reproducidos a través de la educación. Y en este sentido, se hace explicita la mención a "Vigilar y castigar", de Michel Foucault, trabajada en las clases universitarias de André, y que sintetiza en muchos de sus párrafos el debate aquí presentado.

Palabras-clave: Policía; cuerpo; educación; subjetivación política; “Tropa de Élite".
\end{abstract}

\footnotetext{
ABSTRACT

This article is about the film "Tropa de Elite" (2007) -"Golden Bear" ("Goldener Bär") at the Berlin Film Festival (Berlinale) -, working mainly the concepts "body" and "police", and secondarily "education", "politics" and
}

1 Profesor en Educación Física da Universidad Nacional de La Plata(UNLP)Argentina. Magíster en Educación Corporal y Doctorando en Ciencias Sociales en la Facultad de Humanidades y Ciencias de la Educación da Universidad Nacional de La Plata(UNLP). Becario de la Comisión Nacional de Investigaciones Científicas y Técnicas (CONICET). E-mail: eduardogalak@gmail.com 
"political". The main idea is to think the police in a double sense: colloquial and academic. Through the characters of Nascimento and André Matias, this paper shows the lives of two police officers with different life-stories. This allows us to think critically, thanks to the theory of "political subjectivity", and to analyze the disciplination of the bodies, embodied and reproduced through education. This movie makes an explicit reference to "Discipline and Punish" by Michel Foucault, worked in André's college classes. This book synthesized in many of its paragraphs the discussion presented here. Keywords: Police; body; education; political subjectification; "Tropa de Elite".

\section{El cuerpo y la policía. una mirada desde la película "Bope: Tropa de Élite"}

Todo comienza - como no podía ser de otra manera en una trama como la que presenta José Padilha, director de "Tropa de Élite" - con una decisión política. Situada en la Río de Janeiro del '97, la película expone las vicisitudes de un grupo de la tropa de élite de la policía - conocida como BOPE -, a quienes se les ha encomendado la tarea de contener la favela del "Morro do Turano", lugar de traficantes y delincuentes, en vistas a la visita del por entonces Papa Juan Pablo II. Mediante incursiones constantes a ese territorio de nadie, un grupo de policías comandados por Nascimento (Wagner Moura) comienza a mostrar cada vez más dudas y cada vez menos certezas de acatar la ley, cuestión que se entremezcla con la historia de André Matias (André Ramiro), un estudiante de la Facultad de Derecho y parte de la tropa de élite que pone de relieve el cruce entre policía, legalidad, educación y Estado.

Contado intercalando momentos, el film atravesará las prácticas policiales con las clases de André en la Universidad. Será precisamente a partir de la historia de éste que centraremos este trabajo en el que nos dispondremos a analizar la construcción del cuerpo del cuerpo de policías, sus subjetividades puestas de relieve en el aprendizaje - y cómo manejan la legalidad, en función de los conceptos de lo político y la política. Teniendo como eje el libro de Michel Foucault "Vigilar y Castigar", André tendrá que hacer su trabajo práctico de la Universidad y que le permitirá formar grupo con quienes se involucrará para definir la trama de la película, que le hará poner en cuestión sus saberes eruditos acerca de la legalidad y sus prácticas como aprendiz de uniformado. Si bien este libro Foucault lo piensa para una realidad completamente distinta a la de la película - las políticas carcelarias francesas y los contextos europeos, bien 
distinta a la situación brasilera -, utilizaremos como herramienta este libro y los conceptos de este autor, fundamentalmente los de anatomía política del detalle, cuerpos disciplinados, gubernamentalidad, entre otros; por ser explícitamente trabajados en "Tropa de Élite" y por presentarnos un cúmulo de saberes para (re) pensar nuestras prácticas.

El desarrollo de este trabajo estará dividido en tres partes en una especie de adentramiento paulatino desde la teoría hasta la especificidad del tratamiento de la policía (en una doble lectura coloquial y académica) y los cuerpos en André y Nascimento.

\section{Esbozos conceptuales: la política, lo político y la policía}

¿Qué es lo político? Con esta pregunta enmarca Jacques Rancière la discusión en "Política, identificación y subjetivación" acerca de lo que podemos comprender por lo político, relacionándolo con los conceptos de la política y la policía, entendiendo que es en el cruce entre estos tres conceptos en donde podremos encontrar herramientas para pensar el problema aquí planteado. Desde la concepción de este autor, lo político es el encuentro de dos procesos heterogéneos: el de gobernar y el de la igualdad. El primero de ellos, que nombrará como la policía, entraña crear el sentimiento de comunidad, cuestión que descansa en la distribución de participaciones y en la jerarquía de lugares y funciones. El segundo, el de la igualdad o emancipación: prácticas guiadas por la suposición de que todos somos iguales y el intento por verificarlo (lo único universal en la política es la igualdad, un universal que hay que suponer, verificar y demostrar en cada caso). Rancière comprende a estos dos procesos inconmensurables: no es que la policía niegue la posibilidad de la igualdad, sino que la primera daña a la segunda.

[...] consideraré lo político como el lugar donde la verificación de la igualdad se convierte necesariamente en el manejo de un daño. Así que tenemos tres términos: policía, emancipación y lo político. Si queremos poner de relieve su acción recíproca, podemos llamar política al proceso de emancipación. Por consiguiente propongo distinguir entre policía, política y lo político, en donde lo político es el terreno para el encuentro entre la 
emancipación y la policía en el manejo de un daño (RANCIÈRE, 2000, p. 146).

Entonces, la policía estaría inscripta en el registro del orden y de la reproducción, mientras que la política se inscribiría en el registro de la verificación de la igualdad, de la emancipación. Es interesante notar aquí hasta que punto ambos son transversalmente parte de los sistemas educativos - como es la Academia para Policías a la que André y Nascimento asisten -: el primero, por la reproducción de lógicas de disciplinamiento; el segundo, porque solo conociendo esas lógicas es que es posible pensar en una autonomía (relativa) de ellas.

Si bien partiremos de la concepción de Rancière, son varios los autores que han trabajado esa temática desde distintos ángulos, de quienes tomar sus análisis para enriquecer el debate. Por ejemplo, Schmitt, uno de los precursores, proponía pensar al concepto de lo político en relación con el de Estado, entendiendo que la mayoría de las veces esta palabra es empleada sólo en un sentido negativo, a modo de contraste contra muchos otros conceptos. "En general lo 'político' es equiparado con lo 'estatal' o, al menos, se lo relaciona con ello. El Estado aparece, pues, como algo político; y lo político como algo estatal - evidentemente un círculo insatisfactorio" (SCHMITT, 1998). Entonces, el concepto de Estado presupone a lo político, lo político es anterior al Estado. Explícitamente expuesto bajo el subtítulo de "La diferenciación de amigos y enemigos como criterio de lo político", Schmitt propone pensar que lo político surge en la distinción entre amigos y enemigos, en lo colectivo y en su lucha. La categoría de enemigo refiere a una alteridad que amenaza, a un "ellos", en la que ese enemigo no puede ser individual sino colectivo y público. En tanto a la política la pensará más allá de los partidos políticos, sentando las bases para pensar a lo político como una experiencia ubicua y desterritorializada (ARDITI, 2005, p. 2). Dentro del Estado no hay política, hay policía: para Schmitt sólo hay política en plano internacional.

Ahora bien, a partir de lo expuesto por Arditi, enumeraremos otros autores que han pensado la relación teórica entre la política y lo político: a) Lefort entendía que lo político indica el modo de institución de una sociedad, el proceso mediante el cual la sociedad a pesar de sus divisiones se unifica; en tanto la política es la esfera particular de la actividad política y donde se forma y se reproduce un dispositivo general de poder. Lo político es entonces un momento simbólico que funda al orden social mientras que la política es concebida como un subsistema, como las instituciones de ese orden social. b) Žižek, en cambio, propone hablar de una doble inscripción de lo político, y según quien la política: 
oscurece el principio general que genera orden y al mismo tiempo lo hace visible. Este se torna visible en la medida en que las huellas del momento instituyente de lo político están presentes en el subsistema a través del enfrentamiento entre colectivos con proyectos contrapuestos, pues estas luchas continuamente ponen en juego la forma del orden existente y con ello revelan el carácter contingente de toda objetividad. Pero al mismo tiempo, ese principio se oscurece cuando se reduce lo político a un mero subsistema entre otros, olvidándose que la puesta en sentido y la transformación de lo instituido puede darse en cualquier lugar (ARDITI, 2005, p. 2).

c) En tanto Foucault entendía a la política como la continuación de la guerra. Esta, como modo de institución, permanece alojada en la política dentro del subsistema político. En esta línea, d) Laclau se refiere a lo político y lo social como la institución y lo instituido: lo político " $[. .$.$] tiene un papel primariamente estructurante porque las$ relaciones sociales son en última instancia contingentes, y cualquier articulación que prevalezca proviene de una confrontación antagónica cuyo resultado no está predeterminado" (LACLAU, 2006, p. 20).

Por su parte, Arditi propondrá pensar lo siguiente:

La concepción de la política como actividad que se desarrolla en una esfera específica es un fenómeno relativamente reciente asociado con la modernidad politica y la democratización del liberalismo. El giro moderno puede ser descrito como un cambio en la manera en la cual se concibe la idea de orden. Desde el siglo XVII en adelante el pensamiento comienza a alejarse de la derivación teológica del orden a partir de la naturaleza, que es la obra de Dios, y se desplaza hacia una concepción del orden como construcción [...] Para los modernos, pues, el orden es un artificio, una tesis que Nietzsche radicalizaría más tarde al decir que en vez de una armonía inicial sólo hay un juego de fuerzas que funciona como el terreno primario, constitutivo, a partir del cual se debe pensar la creación de todo orden. [...] La modernidad, pues, es una respuesta secular a la ausencia de un fundamento último de las cosas (ARDITI, 2005, p. 6). 
Esa cuestión del orden será profundizada cuando trabajemos el concepto de arkhé.

Ahora bien, profundizaremos el concepto de la policía en el tercer apartado, gracias a los aportes de Foucault, en un cruce entre lo teórico y la película. En el siguiente, analizaremos el concepto de subjetivación política, enfocándolo desde la trama de "Tropa de Élite", observando que es allí donde comenzaremos a encontrar algunas claves para pensar las distintas posibilidades educativas.

\section{La subjetivación política de André y de Nascimento}

“¿Qué es un proceso de subjetivación? Es la formación de un 'uno’ que no es un yo sino la relación de un yo con otro. [...] un proceso de subjetivación es un proceso de desidentificación o desclasificación. Dicho de otra forma, un sujeto es alguien que no pertenece, un extraño, o más aún, alguien que está entremedio (in-between)" (RANCIÈRE, 2000, p. 148-149). Esta subjetivación como cruce de identidades la analizaremos en los personajes de "Tropa de Élite", partiendo de ahí, buscando puntos de contacto con la teoría de Rancière, para retornar otra vez a la película.

La subjetivación política, afirma Rancière, se da por tres razones principales. Como primera razón, propone una subjetivación que no se da individualmente sino porque nunca es la simple afirmación de una identidad, sino que siempre es al mismo tiempo el rechazo de una identidad dada por otro. El orden dominante de la policía, que literal y metafóricamente podemos ver en la historia de André, tiene que ver con los nombres 'correctos', nombres que anclan a la gente a su lugar y a su trabajo, distintos de la política que son los nombres 'incorrectos'. En nuestro caso, es en la política que pretende eliminar la delincuencia de las favelas por acercarse la fecha de arribo del Papa, en la política de enviar a una guerra de todos contra todos, sin medir las consecuencias y sin contemplar el embarazo de Rosane (María Ribeiro), ni sus pedidos para que Nascimento salga del frente; en donde se reflejará con mayor crudeza esta distinción con la policía: expresadas las palabras de Foucault en "Vigilar y Castigar", la narración acerca de André denota el intersticio creado entre la policía y la política, el punto medio entre su obligación como policía y la legalidad que lleva incorporada (hecha cuerpo) con su rol como "intelectual social", formándose como sujeto en ese in-between, en ese "entre". Como pensador crítico de una sociedad que lo rodea, André entiende que la realidad no es aquello que él pensaba, que en la favela sólo encontraría violencia y que 
la única manera de instaurar el orden es mediante la dominación, la represión de su tropa, la policía.

Como segunda razón, la emancipación es una demostración que siempre supone otro, una política, que entraña una identificación posible. Una emancipación, otra vez literal y metafórica, en la búsqueda de Nascimento de un reemplazo para poder dejar "las fuerzas", para no sufrir (y no hacer sufrir) por tener la duda de si podrá ver a su hijo nacer. Un otro para sustituirlo cuyas cualidades oscilen entre las de sus nuevos reclutas: la valentía de Neto (Caio Junqueira) o la inteligencia de André Matias; aunque si él pudiera reunir esas dos mismas cualidades buscadas en uno solo ya hubiera encontrado reemplazo. Otra vez, sujeto a (de) un entremedio, sujeto por ese in-between.

Como tercera razón para la subjetivación política, para la heterología, esta lógica de la subjetivación siempre entraña una identificación posible. Y a continuación Rancière expone que esta subjetivación política depende de la diferencia entre la voz y el cuerpo. Si bien no es trabajado en el mismo sentido estricto, esto último nos da pie para introducir una relación con la obra de Foucault, a partir del cual enfocaremos el tercer apartado en el que analicemos la cuestión corporal y la policía.

\section{La ley en el cuerpo. Tres Lecturas De Michel Foucault}

Voz en off: "En su cabeza estudiar derecho tenía todo que ver con trabajar en la policía. Para él, el policía y el abogado tenían la misma misión en la vida. Ellos tenían que defender la ley" - Diálogo de la película "Tropa de Élite".

En sentido similar, podemos analizar la cuestión de la policía - en relación con la política y con lo político - a través de un enfoque sobre la construcción del cuerpo. Para ello, nos valdremos de tres escritos de Foucault que en distinta medida nos ayudan a esgrimir un argumento acerca de cómo la ley - y la policía - se constituyó en (los) cuerpos, pudiéndolo ver reflejado en la policía de élite de Río de Janeiro²: con Vigilar y Castigar ("Los cuerpos dóciles") por ser un cruce directo con la trama de la película, con la entrevista titulada "Poder-cuerpo" por

2 Es oportuna aquí la pregunta de si las herramientas que Foucault construyó para una realidad europea pueden ayudarnos a pensar la particularidad contextual brasilera. La justificación de tal recurso se encuentra en que nuestros contextos latinoamericanos han sido colonizados por los europeos, incorporándose prácticas, sistemas de gobierno, sistemas educativos. Más aún, reflejados en los modos de narrar las historias, las formas "brasileñas" de filmar, con sus interesantes características propias, son, también, hijas de la modernidad occidental capitalista europea-norteamericana. 
reconstruir al cuerpo como blanco de poder y con "La 'gubernamentalidad" por trabajar sobre la relación entre el Estado y la policía.

Precisamente será en este último texto en el que Foucault analizará a la policía como uno de los elementos a partir del cual se ha podido producir la gubernamentalización de los Estados modernos occidentales (FOUCAULT, 1980, p. 215). Una idea de gubernamentalidad, un arte de gobernar descubierta en el siglo XVIII y con reminiscencias a la ética clásica y al poder pastoral, entendida como un conjunto constituido por las instituciones, los procedimientos, análisis y reflexiones, los cálculos y las tácticas que permiten ejercer el poder sobre la población, como forma primordial de saber, la economía política, y como instrumento técnico esencial, los dispositivos de seguridad; "como resultado del proceso por el que el Estado de justicia de la edad Media, convertido en los siglos XV y XVI en Estado administrativo, se vio poco a poco "gubernamentalizado"'. Es que precisamente Foucault entiende, como hemos visto, que la ciencia de gobernar bien el Estado es una competencia de la política, y que ésta se relaciona con el gobierno de sí mismo (la moral) y con el de la familia (la economía). Estas en un sentido descendente - sí mismo, familia, Estado - cuando son bien gobernadas son denominadas como la policía. "Respecto de la noción de policía, los autores de la época (siglos XVI y XVII) no entendían una institución o un mecanismo en el seno del estado, sino "una técnica de gobierno propia del Estado"” (CASTRO, 2004, entrada "Razón de Estado"). Una idea de gubernamentalidad que estará puesta en discusión a partir de François de La Mothe Le Vayer y su análisis antimaquiveístico del poder encarnado en el cuerpo del Rey, cuestión trabajada en Poder-Cuerpo.

En relación al análisis que ha visto Foucault sobre los procesos que dieron inicio y continuidad a la Modernidad, Lefort expresa que las democracias actuales (como la del Brasil) son una forma particular de lo político que mantiene vacío el lugar de poder, distinto de cómo se concebía en las monarquías en las que el poder estaba corporizado en el Rey, como lo analizaba Arditi. El poder (monárquico) era un poder que se incorporaba, se encarnaba en la persona que ocupe el trono, sólo estando debajo de la ley y la sabiduría divina. A la vez poseedor de un cuerpo inmortal, sobrenatural y de un cuerpo natural, mortal; el Príncipe poseía el poder en su propia persona - un poder encarnado -, siendo en consecuencia la Nación parte de su cuerpo, como una totalidad orgánica. "[...] el poder, en tanto era encarnador, en tanto estaba incorporado en la persona del príncipe, daba cuerpo a la sociedad" (LEFORT, 1990, p. 189). En este sentido, podemos afirmar que en los períodos de la Edad Media y el Renacimiento el cuerpo de los hombres era el cuerpo del Rey, a quien se le asignaba la facultad de dirigir los designios de los pueblos por gracia divina 
(FOUCAULT, 1992, p. 111). Al caer el "cuerpo del Rey", por los procesos que conllevaron las revoluciones francesa e inglesa, se instauró en Europa una nueva regulación de los cuerpos, esta vez, sobre los cuerpos sociales, sobre la población. El principio del fin de la monarquía, la creciente industrialización y el éxodo a las ciudades, hizo necesario que aquello que producían las prácticas ascéticas religiosas fuera funcional a los nuevos modelos económicos, estatales y sociales que se instauraban a lo largo y a lo ancho de la Modernidad occidental, de los que la fábrica y la escuela fueron las instituciones vehículo (GALAK, 2009, p. 274).

- [...] para Foucault el derecho penal es una manifestación de las relaciones de poder y que en verdad no hay ningún contrato social. ¿Entendieron? y que el estado siempre administra instituciones. Palabra dificil, ¿verdad? Instituciones para vigilar y sancionar a los criminales. Como el parágrafo uno relata acerca de esa prisión de la época. Muy loco. Para Foucault el análisis histórico de esas instituciones revela como el Estado ejerce el poder sobre la sociedad - Diálogo de la película "Tropa de Élite".

En cambio, y siguiendo con Lefort, con el advenimiento de la democracia, la noción de poder se encuentra como en un espacio vacío, y quienes ejercen la autoridad política son simples gobernantes y no pueden apropiarse del poder, es decir, incorporarlo. Parecería ser, entonces, que ese cuerpo del Rey devino en la policía como cuerpo social, encarnadora de un poder regulador encargado de generar cuerpos dóciles, manipulables, dando cuerpo a la sociedad.

Entre las transformaciones de las prácticas disciplinarias durante la época clásica, Foucault señala la estatización de los mecanismos disciplinarios. [...] a pesar de que la organización centralizada del aparato policial pueda ser vista como una expresión del absolutismo monárquico, esto es, a pesar de que constituya un aparato de Estado, la función de policía es coextensiva con el cuerpo social; debe llegar hasta sus límites extremos, hasta los mínimos detalles. En este sentido, el objeto de la policía no es el Estado o el reino como cuerpo visible del monarca, sino "todo lo que sucede", "las cosas de cada instante" (CASTRO, 2004, Entrada "Absolutismo"). 
Una política del detalle, una disciplina ${ }^{3}$, una anatomía política del detalle.

Esa cuestión nos permite introducirnos en "Vigilar y Castigar", al igual que ocurre en "Tropa de Élite" en las clases universitarias de André, para analizar a los cuerpos, la educación y los mecanismos disciplinarios:

Ha habido, en el curso de la edad clásica, todo un descubrimiento del cuerpo como objeto y blanco de poder. Podrían encontrarse fácilmente signos de esta gran atención dedicada entonces al cuerpo, al cuerpo que se manipula, al que se da forma, que se educa, que obedece, que responde, que se vuelve hábil o cuyas fuerzas se multiplican. El gran libro del Hombremáquina ha sido escrito simultáneamente sobre dos registros: el anatomo-metafísico, del que Descartes habia compuesto las primeras páginas y que los médicos y los filósofos continuaron, y el técnico-político, que estuvo constituido por todo un conjunto de reglamentos militares, escolares, hospitalarios, y por procedimientos empiricos y reflexivos para controlar o corregir las operaciones del cuerpo. Dos registros muy distintos ya que se trataba aqui de sumisión y de utilización, allá de funcionamiento y de explicación: cuerpo útil, cuerpo inteligible. [...] la noción de "docilidad" que une al cuerpo analizable el cuerpo manipulable. Es dócil un cuerpo que puede ser sometido, que puede ser utilizado, que puede ser trasformado y perfeccionado. [...] El cuerpo humano entra en un mecanismo de poder que lo explora, lo desarticula y lo recompone. Una "anatomía política", que es igualmente una "mecánica del poder", está naciendo; define cómo se puede hacer presa en el cuerpo de los demás, no simplemente para que ellos hagan lo que se desea, sino para que operen como se quiere, con las técnicas, según la rapidez y la eficacia que se determina. La disciplina fabrica asi cuerpos sometidos y ejercitados, cuerpos "dóciles". [...] La minucia de los reglamentos, la mirada puntillosa de las inspecciones, la sujeción a control de las menores partículas de la vida y del cuerpo darán pronto, dentro del marco de la escuela, del cuartel, del hospital o del taller, un contenido laicizado, una racionalidad económica o técnica a este cálculo mistico de lo infimo y del infinito. [...] Una observación minuciosa del detalle, y a la vez una considera-

3 "A estos métodos que permiten el control minucioso de las operaciones del cuerpo, que garantizan la sujeción constante de sus fuerzas y les imponen una relación de docilidad-utilidad, es a lo que se puede llamar las 'disciplinas"” (FOUCAULT, 2002, p. 141). 
ción política de estas pequeñas cosas, para el control y la utilización de los hombres, se abren paso a través de la época clásica, llevando consigo todo un conjunto de técnicas, todo un corpus de procedimientos y de saber, de descripciones, de recetas y de datos. Y de estas fruslerias, sin duda, ha nacido el hombre del humanismo moderno (FOUCAULT, 2002, p. 140-145).

Se podría pensar, entonces, que con el advenimiento de las democracias, de los Estados Modernos, el poder dejó en algún punto de pretenderse único o igualitario para pasar a pensarse en términos plurales de poderes circulantes (en los cuerpos) que no niegan la diversidad sino que la incorporan con antiguas proyecciones homogeneizantes, como en los casos de André y Nascimento. Así, podemos pensar que la policía, pero también por caso la educación, funciona de manera semejante a la uniformidad, en su doble lectura, monárquica.

Afirmando que la acción política es sobre todo acción simbólica, Ana Teresa Martínez (2003) escribe que la incorporación de disposiciones de poder constituye un suelo invisible de creencias, de creencias en los poderes constituidos, en el lugar que ocupamos en el campo, en la legitimidad de las leyes, en la representación de los representantes. Esto, si bien por momentos se constituye en violencia física - como la de "Vigilar y Castigar" -, se traduce fundamentalmente en violencia simbólica, es decir, de incorporación no-voluntaria de un arbitrario. La palabra, objeto de su análisis y posible de ser relacionada con "la voz" en Rancière, no tiene autonomía por fuera de las creencias sociales que la sustentan, pero apoyándose en ellas se adquiere una eficacia simbólica transformadora de la realidad social bajo ciertas condiciones.

La dominación, apoyada siempre sobre un arbitrario legitimado, habla el lenguaje del cuerpo, y desde alli construye la representación de su legitimidad, elabora discursos, legisla, regula eficazmente las acciones, asegura la reproducción social, apoyándose en consensos y delegaciones prerreflexivas la mayor parte del tiempo, excepcionalmente conscientes y deliberadas (MARTINEZ, 2003, p. 12).

Una violencia simbólica que se reproduce en las prácticas educativas, ya sea en la escuela, en la universidad o en la academia para aprendiz de policías, 
ya sea en la historia de André o en la de Nascimento; y que se incorpora en los cuerpos.

Como vemos, la "policía" engloba todo: las relaciones entre los hombres y las relaciones de éstos con las cosas, la coexistencia de los hombres en un territorio, las relaciones de propiedad, lo que los hombres producen, lo que comercian. El verdadero objeto de la policía es, en definitiva, el hombre mismo. [...] Entonces la "policía" designa el nuevo dominio en el que el poder político y administrativo del Estado centralizado puede intervenir. [...] En definitiva - y Foucault insiste en ello - el objeto de la "policia" es la vida. Comprendemos esta insistencia de Foucault al respecto en tanto la razón de Estado y la policía se inscriben en el proceso de formación de la biopolítica (CASTRO, 2004, entrada “Razón de Estado”).

El sistema no tiene límites, no tiene fronteras, ya hace parte de la cultura de la policía. El sistema lleva a los policías a la locura [...] pero no es así que la policía funciona. La policía depende del sistema y el sistema no trabaja para resolver los problemas de la sociedad, el sistema trabaja para resolver los problemas del sistema - Diálogo de la película "Tropa de Élite”.

En un punto relacionado con Schmitt y su proposición de que dentro del Estado sólo hay policía o una técnica de gobierno propia del Estado para Foucault, este escribió que

La ciencia de la policía es un arte de gobernar y un método para analizar una población que habita un territorio. Lo que interesa a la policía es la coexistencia de los hombres en un territorio, sus relaciones de propiedad, lo que producen, lo que intercambian, etc. [...] a diferencia de los otros géneros acerca del gobierno, el objeto del gobierno no es el territorio, sino la población (CASTRO, 2004, entradas "Territorio" y "Gubernamentalidad"). 
Esto es, un gobierno sobre los individuos, un gobierno de todo lo que sucede, una anatomía política del detalle, pretendiendo gobernar la subjetivación, un proceso de desidentificación en el que mi formación del yo esté puesta en relación con otro, y en la que ese otro haya sido gubernamentalizado, haya sido cuerpo como blanco y objeto de poder: haya incorporado la policía. En el extremo opuesto Rancière parecería ubicar la política: “[...] la política no es la promulgación o la puesta en escena del principio, ni la ley, ni el ser de una comunidad. En otras palabras, la política carece de arché, es anárquica" (RANCIÈRE, 2000, p. 146). Este arkhé, este principio detrás del orden, es la pura ley hecha cuerpo en la policía. Su incorporación se puede observar, en sentido literal y metafórico, en el cuerpo de los policías André y Nascimento: una legalidad incorporada en y a través de las prácticas (educativas). Parafraseando a Rancière, sus cuerpos estarían en un in-between entre la política y la policía, entre la emancipación y la reproducción, entre sus subjetividades políticas como prácticas de verificación de la igualdad y la policía como el vínculo de la actividad política con los individuos - y con los modos ser y hacer común adquiridos.

\section{Consideraciones finales: la educación incorporada}

Si bien aquí sólo se trabajaron algunas posibles lecturas de una cuestión que excede por mucho la película, los autores citados y los recortes expuestos, resulta interesante remarcar una serie de consideraciones finales a tener en cuenta.

Las posibilidades que brinda la educación para formar una subjetivación política son significativas. Sin embargo, asistimos al proceso contrario al que buscamos como educadores. Ya sea en la academia de aprendiz para policías, en las universidades o en las escuelas, se denota primero la enseñanza de la legalidad, de la normatividad, de la docilidad, tibiamente construyendo la posibilidad y apenas dejando entreabierta la posibilidad de libertades. Esquemáticamente, un "in-between" inclinado hacia la reproducción más que a la autonomía, hacia la policía más que a la libertad. Será tarea nuestra, como educadores, buscar las herramientas necesarias para torcer esta historia. Sin lugar a dudas, la primera medida para destronar a la alienación es la toma de consciencia de tal condición.

Y el lugar que ocupe el cuerpo en esta política educativa de subjetivación política deberá ser, como nunca antes ha sido por todos los procesos 
expuestos por Foucault, central. Respetando el lugar que ocupa el cuerpo en nuestras sociedades, construyendo nuevas posibilidades, se podrá pensar en el sujeto crítico que André pretende ser, en los sujetos críticos que busca la educación. En otras palabras, "El cuerpo cree en lo que juega. [...] No representa lo que juega, no memoriza el pasado, él actúa el pasado, así anulado en cuanto tal, lo revive. Lo que se aprende por el cuerpo no es algo que se posee como un saber que se domina. Es lo que se es" (BOURDIEU, 1991, p. 123).

Por último, para finalizar, un diálogo de "Tropa de Élite" que esgrime un punto límite de la subjetivación política a través de la educación - en este caso, universitaria -: la propia experiencia sesgada, a partir del legado reproductivista aprendido de la familia y de lo tendencioso de los medios de comunicación, funciona como límite tajante de las posibilidades de concebir otras realidades.

- Bueno nosotros concluimos por tanto que en Brasil la legislación penal funciona como una red que articula diversas instituciones represivas del Estado, y que infelizmente hoy en nuestro pais el resultado de esta microrelación del poder que Foucault tanto habla acabó creando un Estado que protege a los ricos y sanciona casi exclusivamente a los pobres.

- Muy bien. Finalmente creo que Maria y todo el grupo hablaron con clareza como las relaciones de poder - no sólo el Estado-, moldean instituciones perversas. Ahora para concluir podríamos hacer un análisis con casos. Una institución de ese tipo es la policía. ¿Por qué la policía?

- Profesor, porque todos sabemos que en las favelas los perros llegan pegando, llegan dando golpes y palizas en general.

- Edú tiene razón. La policía actúa perversamente contra los desposeidos, los ignorantes y aquellos que por su condición son obligados a cometer delitos. 
- Yo concuerdo con la opinión de Edú en parte pero yo creo que la policía no actúa perversamente sólo con las clases menos favorecidas porque creo que nosotros, la clase media, la clase alta, también somos víctimas de este bando. Una vez yo, María y Natalia estábamos yendo a Buzios y fuimos paradas en control policial y ellos fueron agresivos con nosotras apuntando armas.

- Mi padre es juez y él me dijo que en la bajada fluminense, tortura es poco que la policía hace. La policía entra allá y sale matando a todos, como la matanza de la candelaria. Es lógico que además de corruptos, ellos sean cobardes de verdad.

- Todos van a hablar, sólo que André Matías está en la fila y levantó el brazo para hablar.

- Sí Gusmão, lo que ocurre es lo siguiente: yo creo que están teniendo una opinión muy superficial de lo que realmente pasa, están muy mal informados. [...] Yo creo que en la policia hay corrupción pero en su gran mayoría los policías quieren hacer un trabajo honesto. [...] Lo que ocurre es lo siguiente: yo tengo un gran amigo que es policía, y el mejor amigo de él, es policía también. Y los dos son honestísimos. Y con relación a lo de Buzios yo creo que tienen que reprimir de verdad, tiene que reprimir verdaderamente. Como que no, amigo Tú estabas con un pito de marihuana ¿verdad? Ustedes no tienen la menor noción de cuántos niños entran para el tráfico y mueren por causa de marihuana y del polvo. De los apartamentos de ustedes aqui en la zona sur no se puede ver eso, no. Ustedes están muy mal informados, están muy mal influenciados por periódicos y la televisión.

- Bueno creo que por hoy podemos terminar... - Diálogo de la película "Tropa de Élite". 


\section{REFERENCIAS}

ARDITI, B. El devenir-otro de la política: Un archipiélago post-liberal. In: ARDITI, B. (Ed.). ¿Democracia post-liberal? El espacio político de las asociaciones. Barcelona: Anthropos, 2005. p. 219-248.

BOURDIEU, P. El sentido práctico. Madrid: Taurus, 1991.

CASTRO, E. El vocabulario de Michel Foucault. Un recorrido alfabético por sus temas, conceptos y autores. Bernal: Universidad Nacional de Quilmes, 2004.

FOUCAULT, M. Vigilar y castigar: nacimiento de la prisión. Buenos Aires: Siglo XXI, 2002.

. La microfísica del poder. Madrid: La Piqueta, 1992.

. Espacios de Poder. Madrid: La Piqueta, 1980.

GALAK, E. El cuerpo de las prácticas corporales. In: CRISORIO, R. Educación Física. Estudios críticos de Educación Física. La Plata: Al Margen, 2009.

LACLAU, E. ¿Por qué construir un pueblo es la tarea principal de la política radical? Cuadernos del CENDES, Caracas, v. 23, n. 62, p. 1-36, ago. 2006.

LEFORT, C. La invención democrática. Buenos Aires: Nueva Visión, 1990.

MARTÍNEZ, A. T. La excepción del lenguaje verdadero. Santiago de Chile, 2003. Disponible en: $<\mathrm{http}$ //acilbuper.webcindario.com/la_excepcion.pdf $>$. Consulta en: 9/8/2009.

RANCIÈRE, J. Política, identificación y subjetivación. In: ARDITI, B. (Ed.). El reverso de la diferencia. Identidad y política. Caracas: Nueva Sociedad, 2000.

SCHMITT, C. El concepto de lo político. Madrid: Alianza, 1998. p. 49-122.

Texto recebido em 2 de outubro de 2009.

Texto aprovado em 13 de maio de 2010. 